\title{
Space-borne BDS receiver for LING QIAO satellite: design, implementation and preliminary in-orbit experiment results
}

\author{
Xi Chen ${ }^{1} \cdot \operatorname{Sihao} \mathrm{Zhao}^{2} \cdot$ Menglu Wang ${ }^{1} \cdot \operatorname{Mingquan} \mathrm{Lu}^{2}$
}

Received: 25 June 2015/Accepted: 8 October 2015/Published online: 19 October 2015

(c) The Author(s) 2015. This article is published with open access at Springerlink.com

\begin{abstract}
Known as China's first low earth orbit (LEO) mobile communication experimental satellite, the LING QIAO satellite was launched on September 4, 2014. In addition to the two global positioning system (GPS) receivers on board, which are the main navigation receivers supporting the synchronized LEO communication payload and other systems that require navigation input, a BeiDou navigation system (BDS) receiver is also installed on board as an experimental payload. We present the system design and preliminary in-orbit experiment results of the BDS receiver of the LING QIAO satellite. The results show that: (1) The root-mean-square positioning error of the BDS receiver is $13 \mathrm{~m}$, while the GPS error is $1 \mathrm{~m}$; (2) the inorbit traced service area of BDS is from $55^{\circ} \mathrm{S}$ to $55^{\circ} \mathrm{N}$, $70^{\circ} \mathrm{E}$ to $150^{\circ} \mathrm{E}$, which matches the official announced service area; (3) for industrial-level chips and devices of the BDS payload which are vulnerable to space radiations, the single-event effect monitoring and combating measures, as presented in this work, have been effective for LING QIAO satellite.
\end{abstract}

Keywords Space-borne BDS receiver - LEO communication satellite $\cdot$ System design $\cdot$ In-orbit performance

Sihao Zhao

zsh_thu@tsinghua.edu.cn

Space Center, Tsinghua University, Beijing, China

2 Department of Electronic Engineering, Tsinghua University, Beijing 100084, China

\section{Introduction}

Recently, there witnessed a new wave of satellite communication constellation plans and constructions. Iridium Communications Inc. is developing Iridium NEXT satellites to refresh its aging first-generation mobile messaging fleet with the first satellite engineering model completed in August, 2014. The O3b satellite constellation, which is designed for telecommunications and data backhaul from remote locations, has been put into services with eight satellites in 2014 (Blumenthal 2013). China's first low earth orbit (LEO) communication experimental satellite, named LING QIAO (NORAD ID: 40136, International code: 2014-051A), was launched on September 4, 2014, with an announcement of 4 satellites to follow. The work was done jointly by Space Center, Tsinghua University and XinWei Telecom Group, China (Jin et al. 2015).

Until now, the LING QIAO satellite has been in operation in space for more than half a year. Unlike Iridium or GlobalStar satellites, which adopt a satellite-fixed mobile communication system, LING QIAO adopted a user-fixed mobile communication system in which wireless communication beams are real-time-adjusted and directed to the users. Such an adaptive communication system maximizes the usage of the limited wireless spectrum; however, it also highly relies on modern global navigation satellite systems (GNSS) to obtain a precise space and time reference under rapid relative movement between LIANG QIAO and the users. The challenges therein for such GNSS receivers are achieving robust positioning and precise timing under a space vehicle movement with a speed about $7.5 \mathrm{~km} / \mathrm{s}$ at $800 \mathrm{~km}$ altitude. In order to meet such requirements, the LING QIAO satellite is equipped with two global positioning system (GPS) receivers on board, which are the main navigation receivers supporting the synchronized 
LEO communication payload and other systems that require navigation input. A BeiDou navigation system (BDS) receiver is also installed on board as an experimental payload and a backup for GPS receivers.

In fact, space-borne GNSS receivers have become a standard component of LEO satellites. Depending on the requirements of different space missions, they have been used for various purposes. At the early stage, they were used for real-time onboard orbit determination (Bertiger et al. 1998; Stieglitz 1999). Recently, an onboard spaceborne GPS receiver can achieve much better orbit determination precision than methods based on ground observations. For example, within the PROBA-2 microsatellite mission, a miniaturized single-frequency GPS receiver based on commercial-on-the-shelf (COTS) technology was employed for onboard navigation with a real-time rootmean-square (RMS) error of $1 \mathrm{~m}$ (Montenbruck et al. 2012). In some scientific space missions, multi-frequency receivers are adopted to collect in-orbit measurements, and off-line orbit determination algorithms are crafted to achieve centimeter-level precise orbit determination. In TerraSAR-X missions, the precise orbit determination based on GPS achieved an accuracy better than $10 \mathrm{~cm}$ from the internal and external orbit assessment (Yoon et al. 2009). For the gravity recovery and climate experiment (GRACE) satellites, GPS data are open to the public for precise orbit determination research purposes. Research has reported centimeter-level results with GRACE GPS data. For example, Kang et al. (2006) achieved an accuracy of about $2 \mathrm{~cm}$ in each axis component. Space-borne GNSS receivers not only can be used for orbit determination of LEO satellites, but also can be used for determining the orbits of satellites whose altitudes are higher than that of GNSS (Garrison et al. 2002). NASA Goddard Space Flight Center (GSFC) had developed a new space-borne GPS receiver, called Navigator, which can operate effectively in the full range of earth orbiting missions ranging from LEO to GEO and beyond. The Navigator employs special signal processing algorithms in radiation-hardened hardware that enables very fast signal acquisition capabilities and improved sensitivity, i.e., a 10-dB improvement over previous space-based GPS receivers whose sensitivity is around $-130 \mathrm{dBm}$ (Winternitz et al. 2009). Space-borne GNSS receivers can also be used as attitude sensors in some space mission (Pendergrass and Treder 2000; Duncan et al. 2010). Due to limited baseline length, the achieved precisions are at $1^{\circ}$ level (Abbas et al. 2013). In recent years, space-borne GNSS receivers are also being used for remote sensing. For example, GNSS-based radio occultation has become an important way of sounding the atmosphere and profiling the ionosphere of the earth (Chiu et al. 2008; Norman et al. 2012; $\mathrm{Li}$ et al. 2014). Space-borne GNSS reflectometry (GNSS-R) has also achieved rapid development nowadays (Fazliani et al. 2012; Park et al. 2012; Lowe et al. 2014; Pascual et al. 2014). Although the future of space-borne GNSS-R is promising, there are still much work to be done for both GNSS-R receiver design and data post-processing.

Whereas GPS is the most mature satellite navigation system, the BDS is a new comer to the modern GNSS club. BDS has been put into regional service since December 2012. The Interface Control Document for Open Service Signal (CSNO 2013b) and the Open Service Performance Standard (CSNO 2013a) have been released. The current BDS space segment consists of five geostationary earth orbit (GEO) satellites, five inclined geosynchronous orbit (IGSO) satellites and five medium earth orbit (MEO) satellites. The GEO satellites are operating in an orbit at altitude of $35,786 \mathrm{~km}$ and positioned at $58.75^{\circ} \mathrm{E}, 80 \mathrm{E}, 110.5^{\circ} \mathrm{E}, 140^{\circ} \mathrm{E}$ and $160^{\circ} \mathrm{E}$, respectively. The IGSO satellites are operating in an orbit at altitude of $35,786 \mathrm{~km}$ and an inclination of 55 to the equator. The right ascension difference in the ascending nodes is $120^{\circ}$ between IGSO orbital planes. The longitude of the intersection point for three of the IGSOs is $118^{\circ} \mathrm{E}$, and that for the other two is $95^{\circ} \mathrm{E}$. The MEO satellites are operating in orbit at altitude of $21,528 \mathrm{~km}$ and inclination of $55^{\circ}$ to the equator. The satellite recursion period is 13 rotations within 7 days. The phase is selected from the Walker 24/3/1 constellation, and the right ascension of ascending node in the first orbital plane is $0^{\circ}$. The four MEO satellites are in the 7th and 8th phases of the first orbital plane, and in the 3rd and 4th phases of the second orbital plane, respectively. Until now, BDS is still a regional navigation system that covers most of the Asia-pacific region (CSNO 2013a, b).

Since the beginning of the regional service of BDS, research results on BDS receivers, signals and performances are increasingly reported. However, most of them are ground based, and very few discuss its applications for space users. In this work, we present the system design of the BDS receiver as well as the GPS receiver and then the preliminary in-orbit experiment results of the BDS receiver of LING QIAO satellite. The results show that: (1) The RMS positioning error of the BDS receiver is $13 \mathrm{~m}$, while the GPS error is $1 \mathrm{~m}$; (2) the in-orbit traced service area of $\mathrm{BDS}$ is from $55^{\circ} \mathrm{S}$ to $55^{\circ} \mathrm{N}, 70^{\circ} \mathrm{E}$ to $150^{\circ} \mathrm{E}$, which matches the official announced service area; (3) the single-event effect monitoring and combating measures designed for the industrial-level chips of the receiver, as presented in this work, have been effective on LING QIAO satellite.

\section{The navigation subsystem of LING QIAO}

The navigation subsystem of LING QIAO provides precise time, position and velocity for other subsystems including the space mobile communication payload of the satellite, 
Fig. 1 Block diagram of the GNSS navigation subsystem of LING QIAO

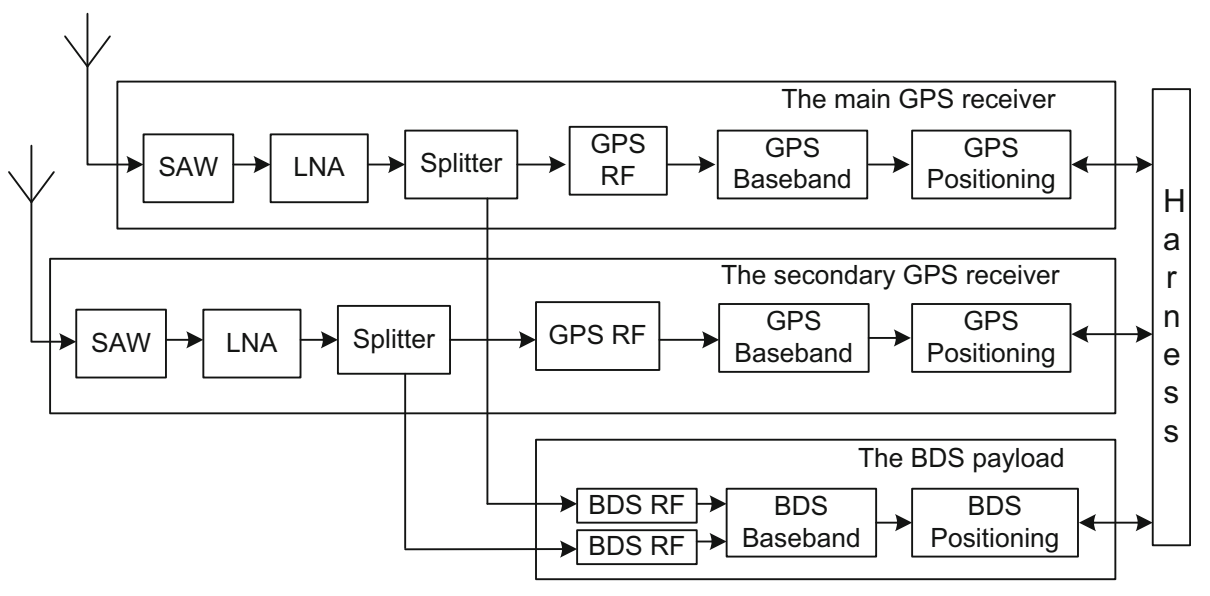

which is one of the most important subsystems of the satellite. In this section, we present system aspects of the LING QIAO navigation subsystem, including its top-level design, hardware system, antenna characteristics, RF path loss and signal processing flow.

\section{Top-level design}

As shown in Fig. 1, the subsystem consists of two GPS receivers and a BDS experimental payload. One of the two GPS receivers works as the main device, and the other one works as the backup. The BDS payload does not have a separate antenna; it shares the receiving antenna with the GPS receivers. The GPS L1 and BDS B1 signals are first fed into a surface acoustic wave (SAW) filter to prevent out-band saturated electromagnetic interference coupled from other radio transmitters on LING QIAO. The signal amplified by the low-noise amplifier (LNA) is split and fed to the BDS radio frequency (RF) modules. The BDS baseband processor selects one of the two inputs as BDS input following the instruction of the LING QIAO ground control station.

\section{Hardware implementation}

The hardware printed circuit board (PCB) photograph of the LING QIAO GPS and BDS receiver hardware is given in Fig. 2. The two GPS receivers share one PCB, and the BDS payload has its own PCB, but the three share the same harness. Power converters are side mounted to facilitate heat dissipation.

Each RF of the GPS and BDS receivers has a separate temperature-compensated crystal oscillator (TCXO) as its clock source. The TCXO has a sine wave output with a 0.5ppm long-term stability and less than $-130 \mathrm{dBc} / \mathrm{Hz} @$ $1-\mathrm{kHz}$ phase noise.

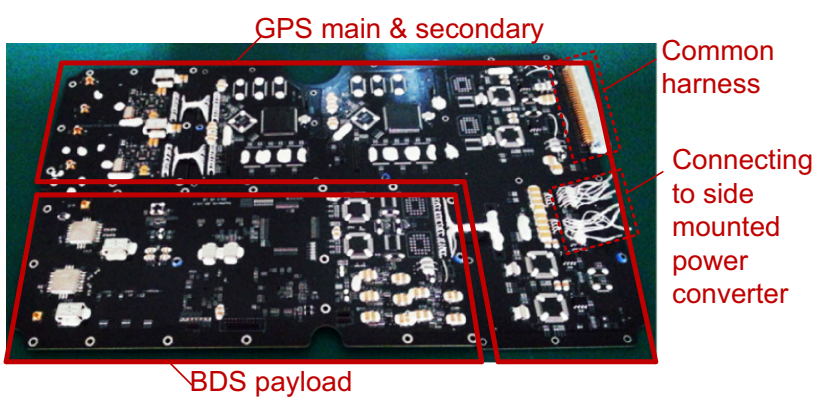

Fig. 2 Photograph of the LING QIAO GPS and BDS receiver hardware

\section{Antenna and RF path loss}

The passband response of the SAW filter in front of the LNA is given in Fig. 3. It has a 1-dB insertion loss for GPS $\mathrm{L} 1$, but has a $2-\mathrm{dB}$ insertion loss with at least 1-dB inband spectrum ripple for BDS $\mathrm{B} 1$. The noise figure of the LNA is about $0.7 \mathrm{~dB}$. The electromagnetic interference (EMI) noise loss caused by other radio systems of LING QIAO is found to be $0.5 \mathrm{~dB}$ in ground EMI tests in a microwave anechoic chamber. Figure 4 gives the GNSS antenna characteristics of LING QIAO. The antenna gain falls to $0 \mathrm{~dB}$ at an elevation of about $15^{\circ}$.

\section{Signal processing flow}

The signal processing flow of both the LING QIAO GPS and BDS receivers is shown in Fig. 5. As is shown, the RF front end is a compact module that coverts RF input into digital intermediate frequency (IF) signal. For the GPS receiver, there are 12 correlators in the acquisition and tracking module, as predetermined by the GP4020 chipset (ZarLink 2002). For the BDS receiver, in addition to 12 correlators, there is another acquisition engine that can correlate 200 code chips in parallel. The BDS acquisition 


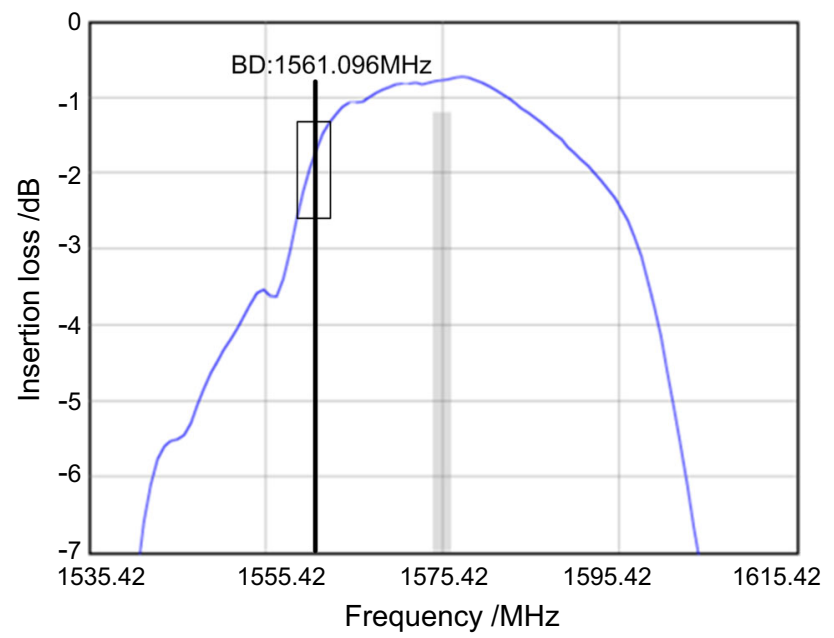

Fig. 3 Passband response of the SAW filter in front of the LNA
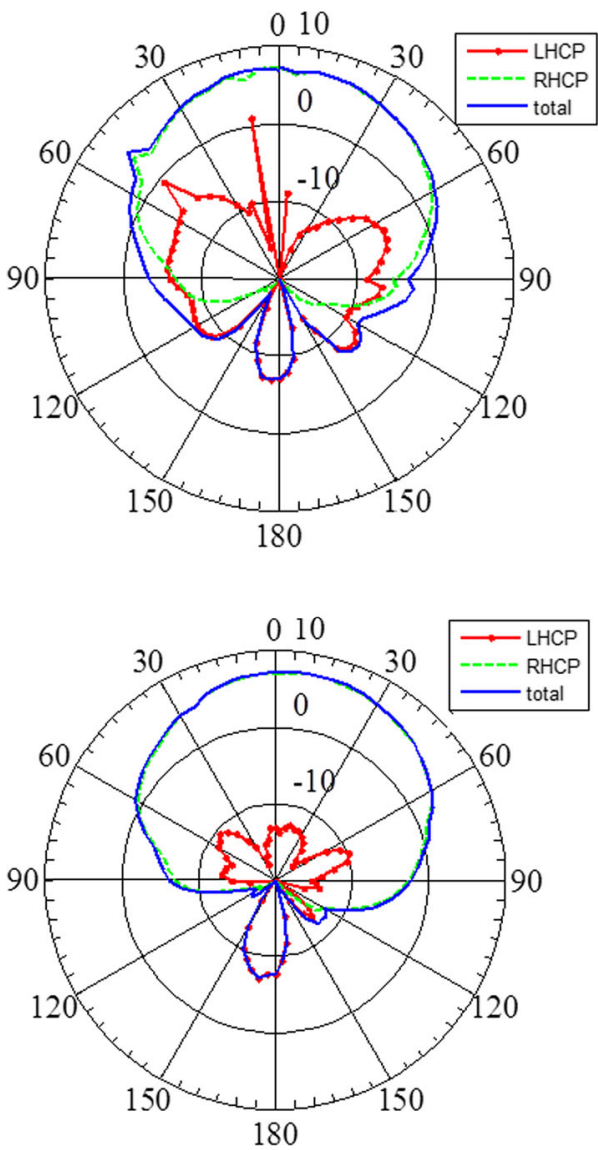

Fig. 4 Receiving antenna radiation pattern (top $\phi=0^{\circ}$; bottom $\left.\phi=90^{\circ}\right)$

and tracking module is implemented on a Xilinx fieldprogrammable gate array (FPGA). Such a BDS acquisition and tracking module helps reduce FPGA logic occupation, which is a main concern for space-borne systems. Outputs

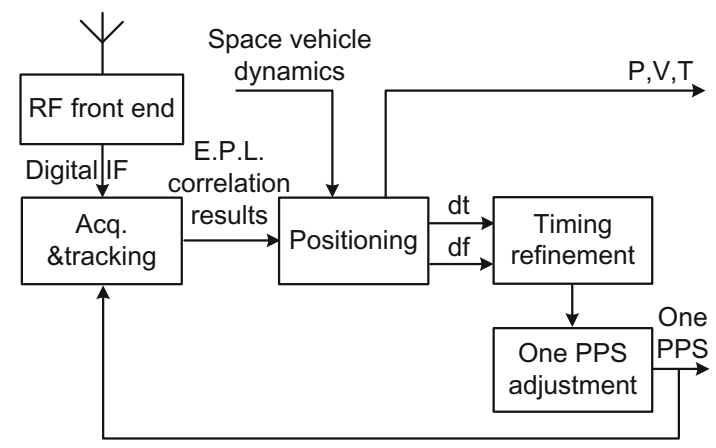

Fig. 5 Signal processing flow of the LING QIAO BDS receiver

of the acquisition and tracking modules are correlation results corresponding to the early, prompt and late $(\mathrm{E}, \mathrm{P}, \mathrm{L})$ codes of the 12 correlators.

In the positioning module, the space vehicle dynamics, specifically the earth gravity with $\mathrm{J} 2$ perturbation, is used for the next epoch position and velocity prediction. Such a prediction is helpful to eliminate measurement outliers before positioning. The calculated time error and frequency error are further sent to the timing refinement module, which refines time and frequency errors based on Reynolds averaging theory borrowed from hydrodynamics (Girimaji 1996). More specifically, the frequency offset ("df" in Fig. 5) between the local clock and the GNSS clock is viewed as the time average of an "eddy flux" - a slowly changing random variable, which can be and is refined by an averaging filter to improve timing precision in our design. The clock error ("dt" in Fig. 5) is viewed as the fluctuations of the "eddy flux" - the random component of the variable, which is compared against a threshold to avoid improper adjustment. The refined time and frequency are then used by the one pulse per second (PPS) adjustment module to calibrate one PPS of the next epoch.

With 12 correlators and all the aforementioned RF loss, the sensitivity of the GPS receivers is found to be $-130 \mathrm{dBm}$, and the BDS payload is $-128 \mathrm{dBm}$ at the antenna output according to both the system design and ground tests. With the antenna gain as given in Fig. 4, navigation satellites with an elevation above about $15^{\circ}$ are expected to be trackable.

\section{BDS coverage}

According to (CSNO 2013a), the current regional BDS provides service for Asia-Pacific area as shown in Fig. 6, which covers most areas from $55^{\circ} \mathrm{S}$ to $55^{\circ} \mathrm{N}, 70^{\circ} \mathrm{E}$ to $150^{\circ} \mathrm{E}$. A 48 -h in-orbit dataset which provides the number of satellites tracked by the LING QIAO BDS receiver is recorded, and the results are plotted in Fig. 7. 


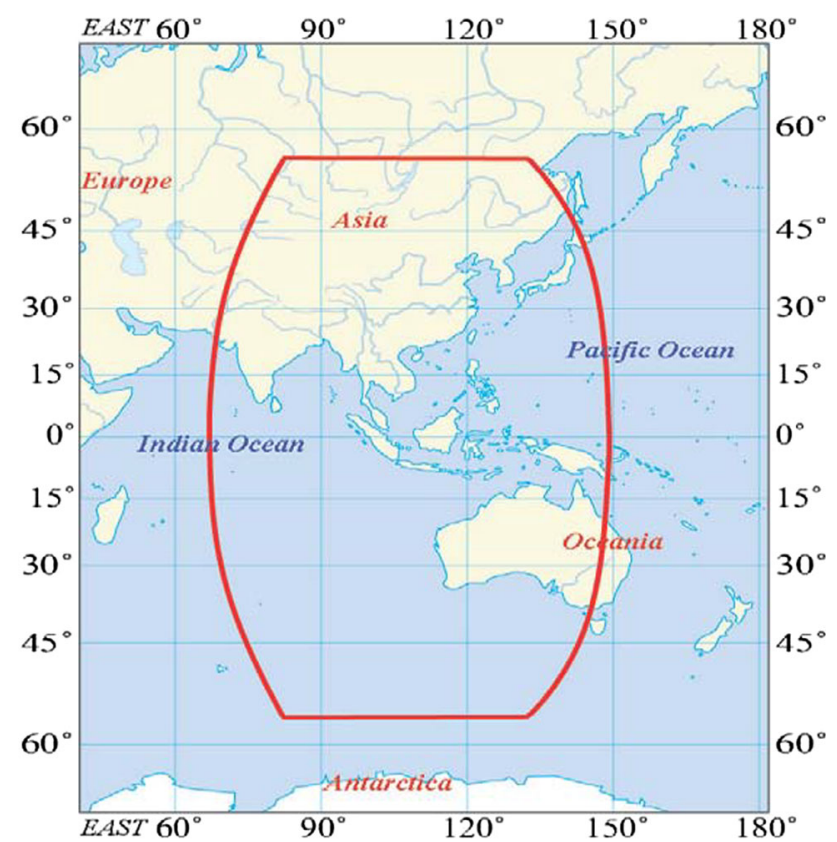

Fig. 6 BDS service area

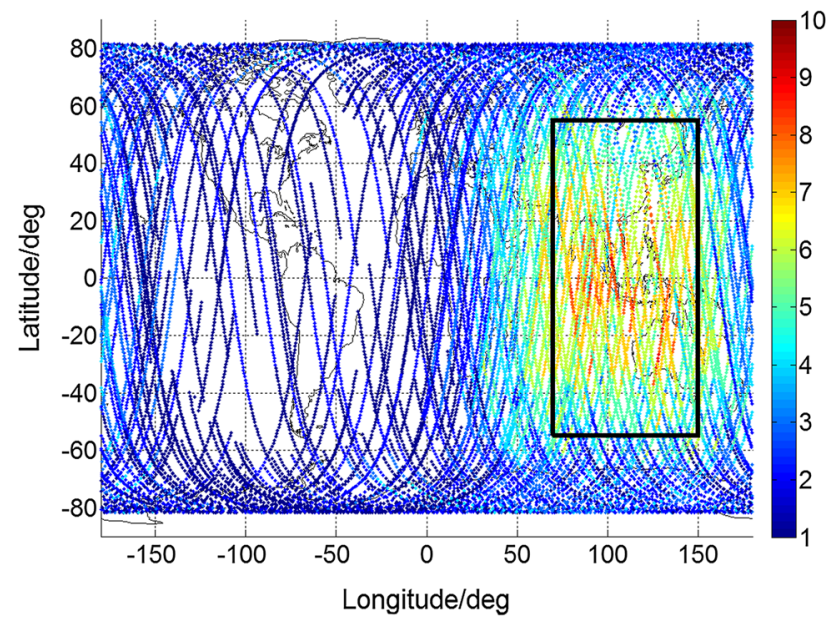

Fig. 7 Number of in-orbit tracked BDS satellites

The black frame in Fig. 7 is the region from $55^{\circ} \mathrm{S}$ to $55^{\circ} \mathrm{N}, 70^{\circ} \mathrm{E}$ to $150^{\circ} \mathrm{E}$ in which the most BDS satellites can be tracked, and the number of in-orbit tracked satellites and its time proportion are listed in Table 1. It can be seen that in most areas inside the BDS service region, the LING QIAO BDS receiver can track at least 4 satellites. However, this performance is still limited, and the LING QIAO-based BDS receiver does not fully exploit the service ability of the BDS constellation due to the design drawbacks of this experimental BDS receiver payload; for example, the Doppler offset prediction algorithm is not applied to the signal acquisition module which limits the number of acquired and
Table 1 Statistics of in-orbit tracked BDS satellites by LING QIAO BDS receiver while in the BDS service region

\begin{tabular}{ll}
\hline Item & Value \\
\hline Maximum number & 9 \\
Minimum number & 1 \\
Average number & 5.7 \\
$\geq 9$ time percentage & $0.5 \%$ \\
$\geq 8$ time percentage & $6.8 \%$ \\
$\geq 7$ time percentage & $28.2 \%$ \\
$\geq 6$ time percentage & $57.4 \%$ \\
$\geq 5$ time percentage & $83.7 \%$ \\
$\geq 4$ time percentage & $94.4 \%$
\end{tabular}

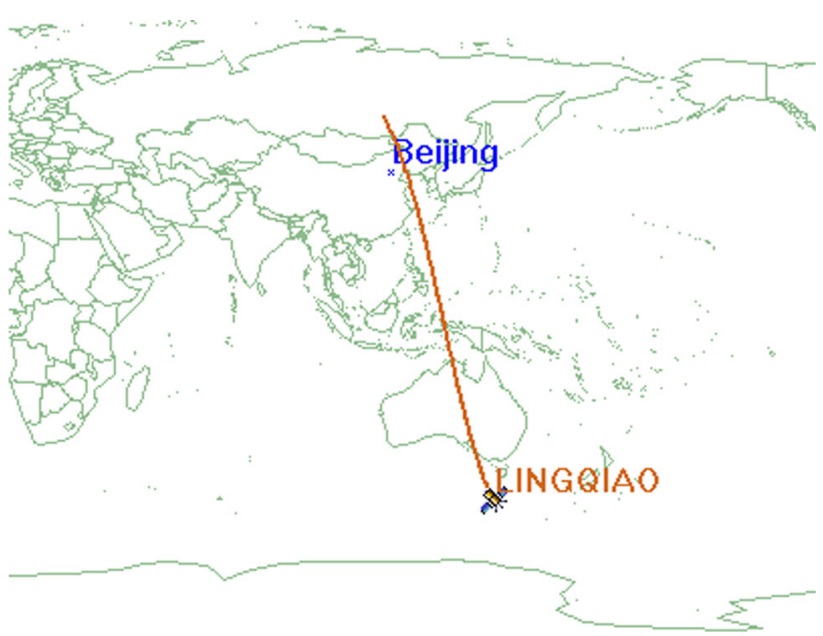

Fig. 8 Ground track of LING QIAO during UTC 2015-05-06, 09:20-09:50

tracked satellites. In the future, the baseband processing program of the receiver will be updated through an in-orbit upgrade and the performance will be improved and the lessons learned from this flight experiment will be applied to future hardware/software designs.

\section{Tracked satellites}

In order to evaluate the signal reception performance of the BDS receiver on LING QIAO, the satellite telemetry data containing the number of the received BDS and GPS satellites are recorded during UTC 2015-05-06, 09:20-09:50 when LING QIAO was orbiting inside the service region of BDS. The ground track of LING QIAO during this period is depicted in Fig. 8.

The theoretical number of BDS satellites in view can be obtained via simulations. The BDS constellation orbital elements as shown in Table 2 during the same period are used to build a simulation situation. The simulated constellation is shown in Fig. 9. 
Table 2 BDS constellation orbital elements (UTC 2015-05-06, 09:20:00)

\begin{tabular}{llllrrr}
\hline Satellite ID & Semimajor axis $(\mathrm{km})$ & Eccentricity & Inclination $\left(^{\circ}\right)$ & RAAN $\left(^{\circ}\right)$ & Argument of perigee $\left(^{\circ}\right)$ & True anomaly $\left(^{\circ}\right)$ \\
\hline G1 & $42,165.688$ & 0.000426 & 1.644 & 14.283 & 167.594 & 321.856 \\
G3 & $42,166.342$ & 0.000329 & 1.558 & 32.018 & 311.138 & 131.181 \\
G4 & $42,165.694$ & 0.000590 & 0.762 & 42.546 & 155.815 & 325.316 \\
G5 & $42,165.450$ & 0.000151 & 1.137 & 29.989 & 76.401 & 315.943 \\
G6 & $42,165.447$ & 0.000118 & 0.192 & 50.414 & 39.299 & 354.017 \\
I1 & $42,154.984$ & 0.003975 & 54.316 & 200.922 & 209.600 & 68.780 \\
I2 & $42,171.079$ & 0.003133 & 53.948 & 320.067 & 196.207 & 324.651 \\
I3 & $42,165.325$ & 0.002474 & 56.986 & 80.834 & 190.779 & 212.815 \\
I4 & $42,159.681$ & 0.003556 & 54.631 & 203.165 & 203.587 & 51.785 \\
I5 & $42,166.455$ & 0.002955 & 54.041 & 319.512 & 195.031 & 303.997 \\
M3 & $27,904.608$ & 0.002209 & 55.818 & 79.941 & 207.192 & 225.624 \\
M4 & $27,905.005$ & 0.002408 & 55.754 & 79.416 & 200.460 & 278.548 \\
M5 & $27,902.630$ & 0.003446 & 54.739 & 199.543 & 168.737 & 106.993 \\
M6 & $27,905.955$ & 0.001893 & 54.844 & 199.144 & 214.668 & 99.547 \\
\hline
\end{tabular}

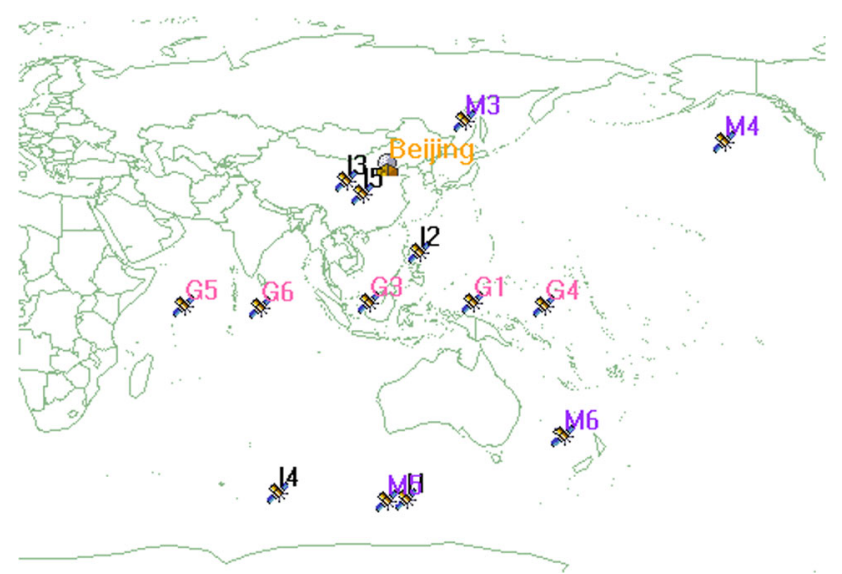

Fig. 9 Simulated BDS constellation at UTC 2015-05-06, 09:20:00

The flight attitude of LING QIAO is three-axis stable, and therefore, the BDS/GPS receiving antenna is always pointing to the zenith. The BDS and GPS receivers share one receiving antenna. According to the antenna pattern shown in Fig. 4, the field of view of the receiving antenna is simply modeled as a cone with the edge corresponding to the 0 -dBi gain. Therefore, the GPS antenna is modeled as a cone with a $150^{\circ}$ apex angle which means the navigation satellite out of this angle of view cannot be received. As mentioned above, the BDS receiver has about $2 \mathrm{~dB}$ more sensitivity loss compared with the GPS receiver, and this loss is equivalent to the loss of the antenna gain. Thus, the BDS receiving antenna is modeled as a cone with a $120^{\circ}$ apex angle in the simulation. The GPS constellation is also simulated as a comparison. The simulated number of satellites and the actual tracked satellites during this period are shown in Figs. 10 and 11.
It can be seen that the theoretical number of GPS satellites in view basically matches the actual number of satellites in view in orbit. This is a proof of the performance of the space-based GPS receiver. However, there is a gap of about two satellites between the in-orbit performance of the BDS receiver and the simulated results as given in Table 3. According to the original design and the ground test results, the possible reason is the lack of a Doppler offset prediction module in the BDS receiver compared with the GPS receiver which causes lower acquisition efficiency and thus a shorter time when the satellites are being tracked in the service region.

\section{Comparison of GPS and BDS in-orbit performance}

As the main time and space reference provider, the GPS receivers of LING QIAO have been working well and support successfully all experiments of other payloads of LING QIAO. Figure 12 gives the position and velocity output by its main GPS receiver.

For the BDS payload, its in-orbit positioning data are recorded and analyzed. Figure 13 gives a trace of position and velocity error (relative to the recovered short arc in least square sense) of both the LING QIAO main GPS receiver and BDS payload for about 10 min during which the satellite is orbiting above China, and thus, the performance is assumed to be "best." As is shown, BDS gives a RMS position error of $13 \mathrm{~m}$ and RMS velocity error of $20 \mathrm{~cm} / \mathrm{s}$. Compared with the BDS receiver, the GPS receiver performs better with a RMS positioning error of $1 \mathrm{~m}$ and velocity error of $1.1 \mathrm{~cm} / \mathrm{s}$ (Fig. 13). 

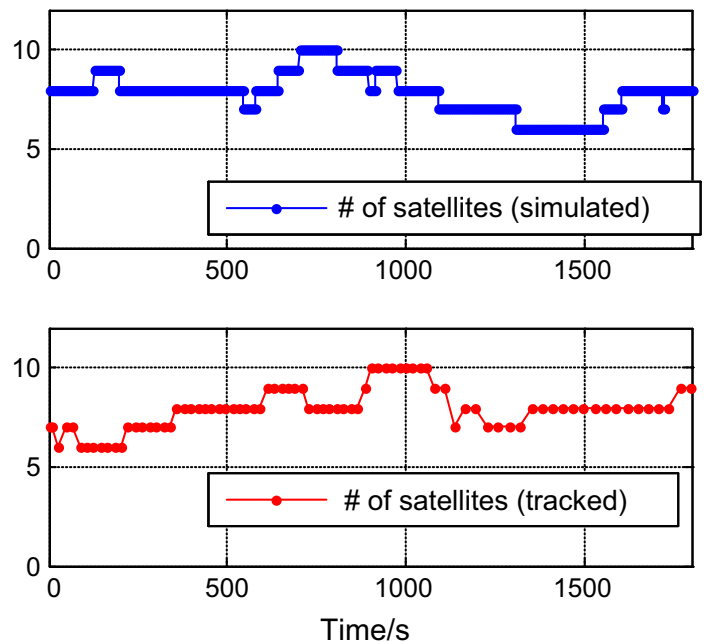

Fig. 10 Comparison of tracked and simulated number of GPS satellites
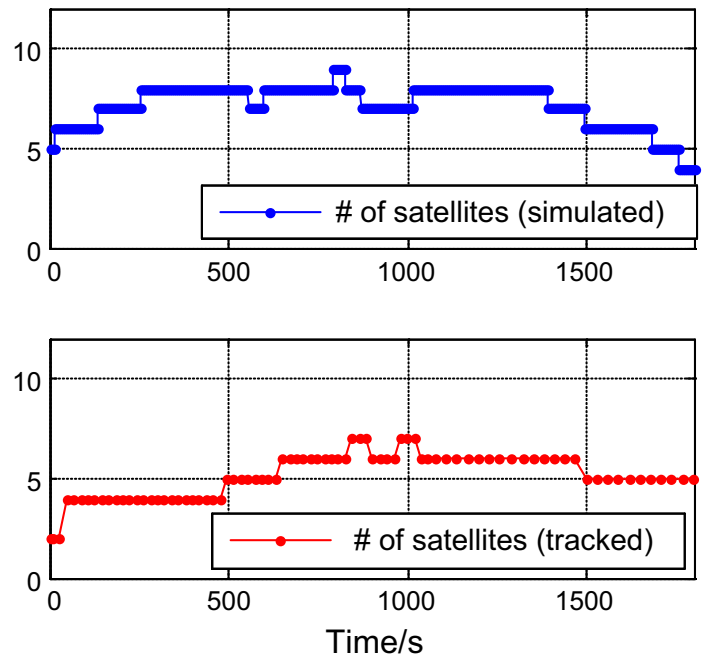

Fig. 11 Comparison of tracked and simulated number of BDS satellites

Table 3 Simulated and actual number of tracked satellites of BDS and GPS

\begin{tabular}{lcll}
\hline & Maximum & Minimum & Average \\
\hline BDS (simulated) & 9 & 4 & 7.21 \\
BDS (in-orbit) & 7 & 2 & 5.12 \\
GPS (simulated) & 10 & 6 & 7.83 \\
GPS (in-orbit) & 10 & 6 & 7.96 \\
\hline
\end{tabular}

\section{Single-event effects}

One important concern at the satellite-based GNSS receiver design stage is the single-event effects (SEE) caused by space radiation which cannot be experienced by a ground
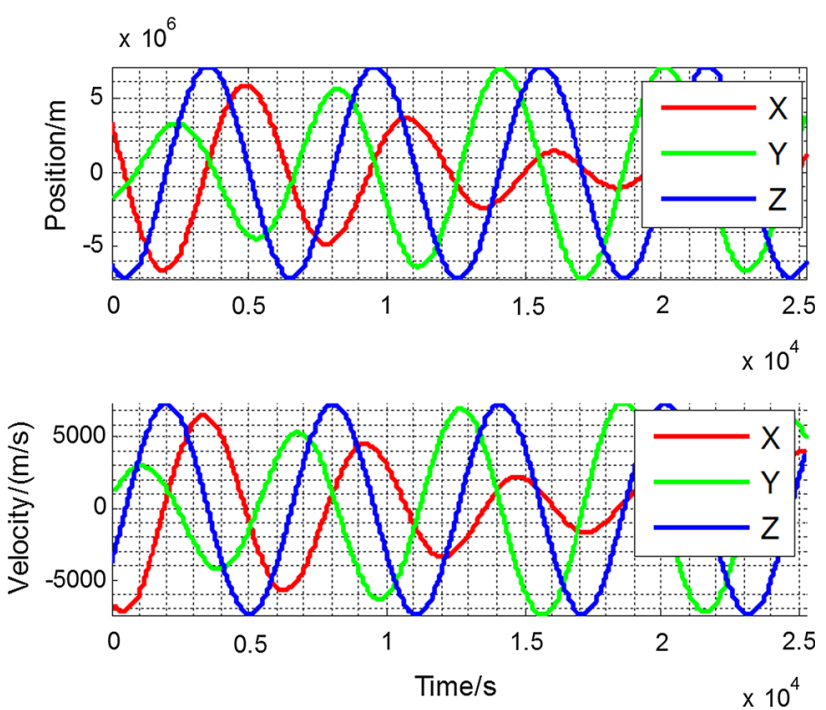

Fig. 12 Position and velocity results from the main GPS receiver of LING QIAO (from UTC 2015-05-06 07:19:38 to UTC 14:19:38)

GNSS receiver. Typical SEE include single-event upset (SEU), single-event latchup (SEL) and single-event function interrupt (SEFI) which may cause malfunctions or even a severe damage to the receiver. Therefore, some SEE monitoring and combating measures are designed in the receiver hardware/software as follows:

1. Power voltage and current outputs are monitored by telemetry;

2. Automatic overcurrent shutdown is implemented to prevent any detrimental overcurrent caused by SEE;

3. Interface circuits are protected by resistances to allow non detrimental overcurrent;

4. Off-chip FLASH memory and static random access memory (SRAM) are protected by triple modular redundancy (TMR);

5. Watchdogs are implemented by a separated logic in anti-fusion FPGA, instead of the built-in watchdog of the ARM processor;

6. Important variables in software are also protected by TMR;

7. Basic working states such as tracked GNSS space vehicle numbers are monitored by software. On exception, the software automatically restarts the whole system;

8. The configuration of SRAM FPGA is done by the ARM processor at boot time to ensure the FPGA configuration is refreshed each time when an ARM processor restarts.

For LING QIAO satellite, the two GPS receivers are implemented based on application-specific integrated circuit (ASIC) so they are expected to be more capable in combating space radiation effects, while the BDS payload 
Fig. 13 Position and velocity error of the LING QIAO main GPS receiver and BDS payload compared with extrapolated orbit
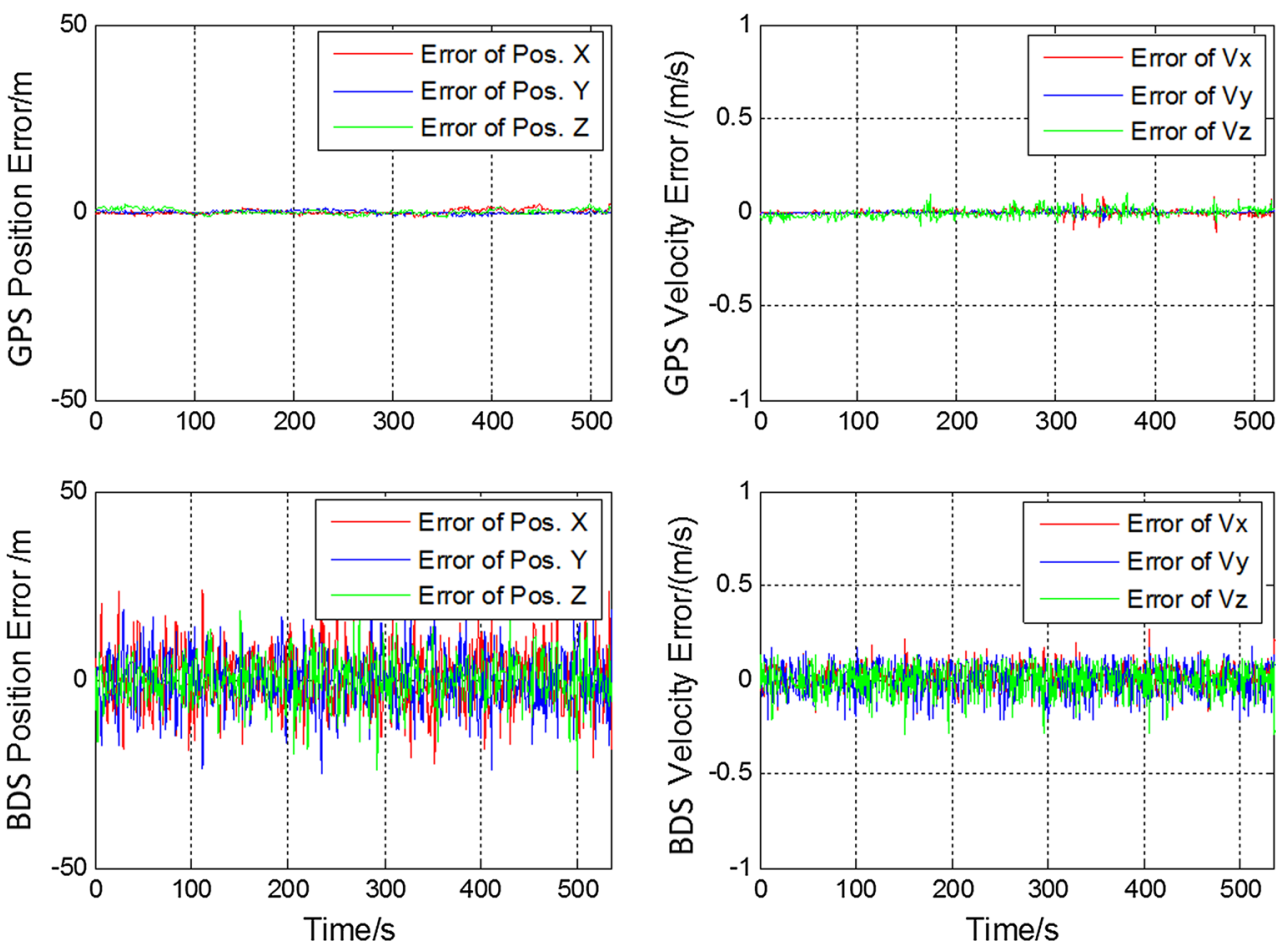

is more vulnerable to space radiations due to the usage of a SRAM FPGA with massive configurable logic blocks.

The main GPS receiver remains powered on during the flight, and we have observed only one SEE. The BDS receiver is powered on only when needed. We powered it on January 20, 2015, and detected a SEE on January 28, 2015. After that, the BDS payload has not been powered on for more than $48 \mathrm{~h}$. Until now, no further SEE have been detected. Details of the SEE tracked by the GPS and BDS receivers are listed in Table 4. Spots of both the SEE experienced by LING QIAO GPS and BDS receivers happened or started in the South Atlantic Anomaly as shown in Fig. 14.

\section{Lessons learned and possible improvement}

From the system design and preliminary in-orbit experiment results, we have learned the following lessons:

1. Due to the limitation of chipsets and reasons of power saving, the current GPS and BDS receivers of LING QIAO have a sensitivity of -128 to $-130 \mathrm{dBm}$.

There are still cases where the number of tracked satellites is lower than the full service capability of both systems, which are caused by the limited sensitivity. For the BDS receiver, improved baseband processing capability including Doppler offset prediction is necessary to increase acquisition efficiency. From analysis and in-orbit results, improved receiver sensitivity, such as $-136 \mathrm{dBm}$ via possible baseband processing software update, is needed to acquire and track more navigation satellites, thus making positioning results more accurate and robust.

2. As components become increasingly smaller, industrial-level very large-scale integration (VLSI) chips can tolerate more total ionizing impact than older generations, but will have become more sensitive to SEU and SEL. So if allowed, payloads should be powered off when in South Atlantic Anomaly.

\section{Conclusions and future work}

In this research, the system design of the BDS and GPS receivers of the LING QIAO LEO telecommunication satellite is presented. The in-orbit performance of this space-borne BDS receiver experimental payload, including the number of tracked BDS satellites and the positioning results, is for the first time reported. The in-orbit traced service area of the current regional BDS matches the officially announced service region which is a verification of the BDS service ability; the position and velocity RMS errors of the BDS receiver reach about $13 \mathrm{~m}$ and $0.2 \mathrm{~m} / \mathrm{s}$. As compared to the GPS receiver on LING QIAO, the performance of the BDS receiver still has some gaps in signal tracking ability and positioning accuracy due to the limitations of the design and mission requirements. Measures to handle the SEE which are different from those 
Table 4 SEE observed by GPS and BDS receiver

\begin{tabular}{|c|c|c|c|c|}
\hline UTC Time & $\begin{array}{l}\text { Latitude, } \\
\text { longitude } \\
\left({ }^{\circ},{ }^{\circ}\right)\end{array}$ & Spot & Phenomenon & Consequence \\
\hline $\begin{array}{l}\text { Event 1: } \\
\text { 2015-1-28 } \\
17: 04: 25\end{array}$ & $\begin{array}{l}(-9.87 \\
-41.94)\end{array}$ & $\begin{array}{l}\text { South } \\
\text { Atlantic } \\
\text { Refer to } \\
\text { Spot A in } \\
\text { Fig. } 14\end{array}$ & $\begin{array}{l}\text { Current of the BDS payload suddenly increased from } 0.32 \mathrm{~A} \\
\text { to } 1.21 \mathrm{~A}\end{array}$ & $\begin{array}{l}\text { The BDS payload was powered off } \\
\text { by the power management system } \\
\text { due to overflow } \\
\text { No anomaly found when powered on } \\
\text { again }\end{array}$ \\
\hline $\begin{array}{l}\text { Event 2: } \\
\text { 2015/5/19 } \\
21: 42: 10\end{array}$ & $\begin{array}{l}(-49.86 \\
-12.03)\end{array}$ & $\begin{array}{l}\text { South } \\
\text { America } \\
\text { Refer to } \\
\text { Spot B in } \\
\text { Fig. } 14 .\end{array}$ & $\begin{array}{l}\text { The GPS main system broadcast stopped, the tracked GPS } \\
\text { satellites dropped to } 0 \text {. After the detection of } 0 \text { tracked } \\
\text { satellite for } 1 \mathrm{~h} \text {, the software restarted automatically }\end{array}$ & $\begin{array}{l}\text { The GPS broadcast service of LING } \\
\text { QIAO was interrupted for about } 1 \mathrm{~h} \\
\text { and } 2 \text { min }\end{array}$ \\
\hline
\end{tabular}

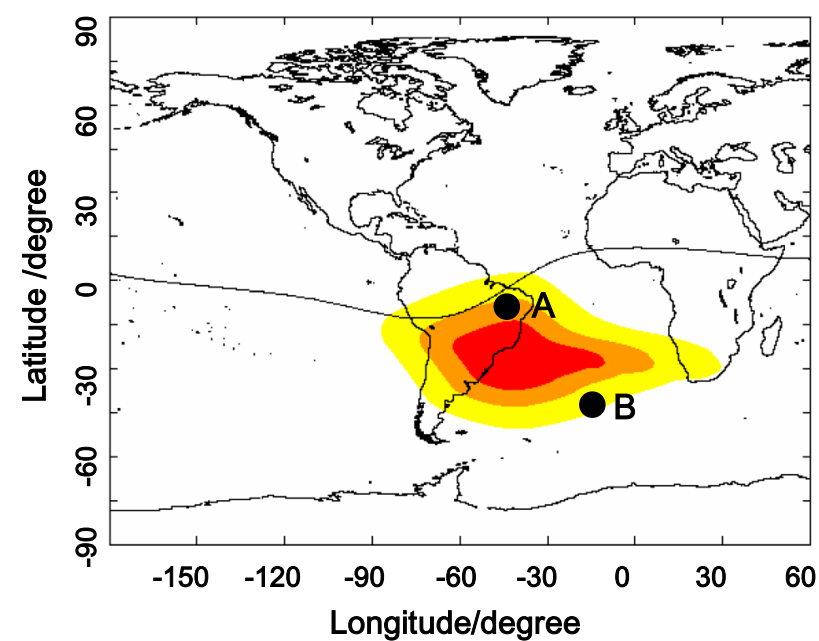

Fig. 14 Spots of the SEE observed by LING QIAO GPS and BDS receivers

ground-based receivers are taken in the system design, and the in-orbit observed events are presented. The lessons learned from our preliminary flight experiments are summarized to guide the future improvement and evaluation work.

We are now working on optimizing the software of the BDS payload which will not only fix the problems found in space but also support a new GPS + BDS joint positioning mode. It is planned to apply this update to the LING QIAO satellite later in 2015. Future work also includes improving positioning algorithm such as incorporating short arc-based filtering that may lead to real-time sub-meter position and $\mathrm{mm} / \mathrm{s}-$ level velocity precision.

Acknowledgments This work is supported by the Open Research Foundation of Science and Technology on Aerospace Flight Dynamics Laboratory under Grant No. 2013AFDL013 as well as China Postdoctoral Science Foundation Grant No. 2014M550732.
Open Access This article is distributed under the terms of the Creative Commons Attribution 4.0 International License (http://crea tivecommons.org/licenses/by/4.0/), which permits unrestricted use, distribution, and reproduction in any medium, provided you give appropriate credit to the original author(s) and the source, provide a link to the Creative Commons license, and indicate if changes were made.

\section{References}

Abbas NN, Li Y, Fiaz M (2013) Attitude determination of small satellite using phase and code measurements of global navigation satellite system: design, simulation and comparison. In: Proceedings of electronics, communications and photonics conference (SIECPC), pp 1-6

Bertiger W, Haines B, Kuang D, Lough M, Lichten S, Muellerschoen RJ, Vigue Y, Wu S (1998) Precise real-time low earth orbiter navigation with GPS. In: Proceedings of ION GPS, Nashville, TN, pp 1927-1936

Blumenthal SH (2013) Medium earth orbit Ka band satellite communications system. In: Proceedings of IEEE military communications conference, San Diego, CA, pp 273-277

Chiu T-C, Liou Y-A, Yeh W-H, Huang C-Y (2008) NCURO dataretrieval algorithm in FORMOSAT-3 GPS radio-occultation mission. IEEE Trans Geosci Remote Sens 46(11):3395-3405

CSNO (2013a) BeiDou navigation satellite system open service performance standard. China Satellite Navigation Office

CSNO (2013b) BeiDou navigation satellite system signal in space interface control document open service signal (version 2.0). China Satellite Navigation Office

Duncan S, Unwin M, Hebden R, Hodgart MS (2010) In-orbit demonstration of a GPS attitude sensor. In: Proceedings of 5th ESA workshop on satellite navigation technologies and european workshop on GNSS signals and signal processing (NAVITEC), Noordwijk, pp 1-8

Fazliani Y, Unwin M, Jales P (2012) Satellite-borne remote sensing: using space GPS/GNSS receiver for reflectometry. In: Proceedings of 6th ESA workshop on satellite navigation technologies and GNSS signals and signal processing, Noordwijk, pp 1-4

Garrison JL, Bertuccelli L, Moreau MC (2002) GPS code tracking in high altitude orbiting receivers. In: Proceedings of IEEE position location and navigation symposium, 2002, pp 164-171 
Girimaji SS (1996) Improved algebraic Reynolds stress model for engineering flows. In: Rodi W, Bergeles G (eds) Engineering turbulence modelling and experiments, vol 3. Elsevier, Amsterdam, pp 121-129

Jin J, Kuang L, Yan J, Chen X, Ni Z, You X, Sun D, Lu J (2015) Smart communication satellite (SCS) — an application oriented micro-satellite for communication. In: Proceedings of AIAA space and astronautics forum and exposition (SPACE), SSC15V-12. http://digitalcommons.usu.edu/smallsat/2015/all2015/ 2031/

Kang Z, Tapley B, Bettadpur S, Ries J, Nagel P (2006) Precise orbit determination for GRACE using accelerometer data. Adv Space Res 38(9):2131-2136

Li Y-S, Hwang C, Tseng T-P, Huang C-Y, Bock H (2014) A nearreal-time automatic orbit determination system for COSMIC and its follow-on satellite mission: analysis of orbit and clock errors on radio occultation. IEEE Trans Geosci Remote Sens 52(6):3192-3203

Lowe ST, Meehan T, Young L (2014) Direct signal enhanced semicodeless processing of GNSS surface-reflected signals. IEEE J Sel Top Appl Earth Obs Remote Sens 7(5):1469-1472

Montenbruck O, Swatschina P, Markgraf M, Santandrea S, Naudet J, Tilmans E (2012) Precision spacecraft navigation using a lowcost GPS receiver. GPS Solut 16(4):519-529

Norman RJ, Dyson PL, Yizengaw E, Marshall JL, Wang C-S, Carter BA, Wen D, Zhang K (2012) Radio occultation measurements from the Australian microsatellite FedSat. IEEE Trans Geosci Remote Sens 50(11):4832-4839

Park H, Camps A, Valencia E, Rodriguez-Alvarez N, Bosch-Lluis X, Ramos-Perez I, Carreno-Luengo H (2012) Retracking considerations in spaceborne GNSS-R altimetry. GPS Solut 16(4):507-518

Pascual D, Camps A, Martin F, Park H, Arroyo AA, Onrubia R (2014) Precision bounds in GNSS-R ocean altimetry. IEEE J Sel Top Appl Earth Obs Remote Sens 7(5):1416-1423

Pendergrass JR, Treder AJ (2000) GPS-updated attitude determination on ISS despite rich multipath. In: Proceedings of AIAA guidance, navigation and control conference and exhibit, Denver, CO, AIAA 2000-4469. http://arc.aiaa.org/doi/abs/2010. 2514/2006.2000-4469

Stieglitz JL (1999) Global positioning system receivers in space applications. In: Proceedings of 18th digital avionics systems conference, St Louis, MO, pp 7.A.3-1-7.A.3-7

Winternitz LMB, Bamford WA, Heckler GW (2009) A GPS receiver for high-altitude satellite navigation. IEEE J Sel Top Signal Process 3(4):541-556

Yoon YT, Eineder M, Montenbruck O (2009) TerraSAR-X precise trajectory estimation and quality assessment. IEEE Trans Geosci Remote Sens 47(6):1859-1868

ZarLink (2002) GP4020 GPS baseband processor design manual. Retrieved 20 June 2015, from http://ulp.zarlink.com/zarlink/hs/ dm5280-design-manual-jan2002.pdf

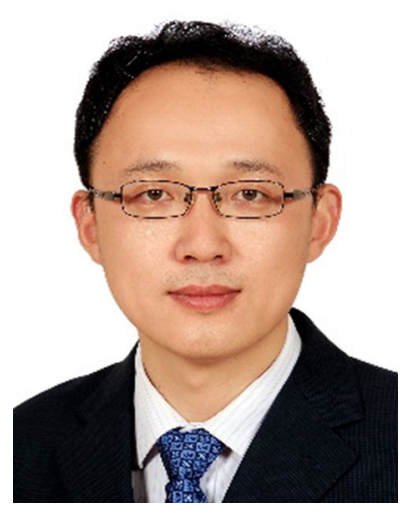

Xi Chen is currently affiliated to Space Center, Tsinghua University, Beijing, China, as an assistant professor. He received his B.S. degree in telecommunication engineering from Beijing University of Posts and Telecommunications, Beijing, China, in 2001 and his Ph.D. degree at the Department of Electronic Engineering, Tsinghua University, Beijing, China, in 2006. His research interests include timing and positioning in space and aero-wireless networks, GNSS positioning, passive locating of active radio sources.

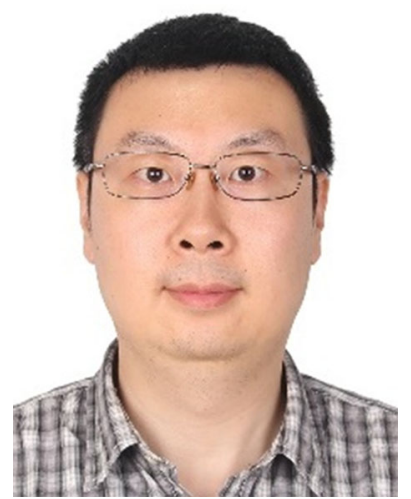

2011, respectively.

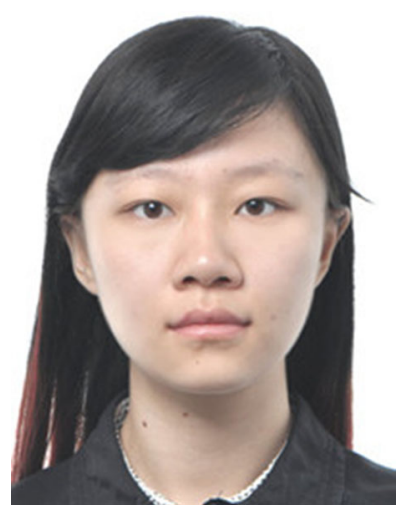

Sihao Zhao is an assistant research fellow at the Department of Electronic Engineering, Tsinghua University, Beijing, China. His research interests include GNSS signal processing algorithms, high-precision positioning techniques, indoor navigation systems as well as telecommunication systems design and verification. $\mathrm{He}$ received his B.S. and Ph.D. degrees from the Department of Electronic Engineering, Tsinghua University in 2005 and

Menglu Wang graduated from Beihang University as a Bachelor in Electronic Engineering and is now pursuing her Master degree in Space Center, Tsinghua University. She is interested in the research of navigation and positioning algorithms, navigation messages and ephemeris for LEO satellites, positioning using Doppler shift of LEO satellites and other GPS/BDS navigation enhancement methods using LEO satellites. 


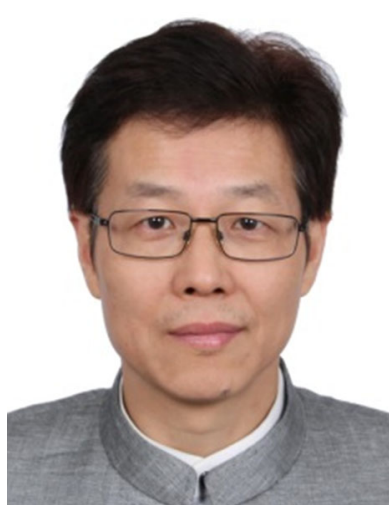

Mingquan Lu is a professor of the Department of Electronic Engineering, Tsinghua University, Beijing, China. He is the director of Tsinghua GNSS Research Laboratory and a member of the Expert Group of China BeiDou Navigation Satellite System. His current research interests include GNSS signal design and analysis, GNSS signal processing and receiver development, GNSS system modeling and simulation. He received his M.E. and
$\mathrm{Ph} . \mathrm{D}$. degrees in Electronic Engineering from University of Electronic Science and Technology, Chengdu, China. 